\title{
Recent Trends in LDC Military Expenditures
}

\author{
RICHARD C. PORTER* \\ University of Michigan, Ann Arbor
}

\begin{abstract}
Summary. - Several alarming and largely ignored trends in the size and structure of military expenditure of less developed countries (LDCs) have appeared during the past quarter century. New, fuller, and better data series permit us to discern four of these recent trends sufficiently clearly to call them "stylized facts" of the contemporary development process: (1) LDC defense expenditures have been rising as a fraction of GDP; (2) the capital cost component of this spending appears to have been rising relative to the operating cost component; (3) the portion of the LDC population serving in the armed forces has been increasing; and (4) LDC military wages appear to have been rising relative to civilian wages.
\end{abstract}

"The cheap defense of nations ... gone." - Edmund Burke

\section{INTRODUCTION}

In the rush to examine and cross-examine Emile Benoit's $(1973,1978)$ conjectures about the relationship of military expenditure and real output growth in less developed countries (LDCs), economists have largely ignored several alarming trends in the size and structure of such spending over the past quarter century. New, fuller, and better data series now permit us to discern four of these trends, perhaps sufficiently clearly to call them "stylized facts" of the contemporary development process:

(1) LDC defense expenditures have risen as a fraction of GDP in the 1970s. For typical LDCs, such expenditures were less than $3 \%$ of GDP in the $1950 \mathrm{~s}$ and $1960 \mathrm{~s}$ but rose to $4 \%$ by 1980 (Section 2).

(2) The capital-cost component of LDC military spending, after falling relative to operating costs in the 1960 s, rose rapidly in the 1970 s. For typical LDCs, equipment costs comprised less than $12 \%$ of total costs over the 1950 s and $1960 \mathrm{~s}$ but had reached nearly $20 \%$ of total costs by 1980 (Section 3).

(3) The fraction of the LDC population serving in the armed forces has also risen rapidly in the $1970 \mathrm{~s}$. On average, in the $1960 \mathrm{~s}$, only onethird of $1 \%$ of the population was in the military; by 1980 , the percentage had reached nearly onehalf of $1 \%$ (section 4 ).

(4) The LDC military "wage" - more precisely, the operating (i.e., noncapital) costs per warrior relative to civilian income per capita rose dramatically in the 1970 s after falling in the 1960s. Although the evidence differs somewhat for different regions of the Third World, the typical LDC lowered the relative military "wage" by $20 \%$ in the 1960 s, only to raise it back up by that $20 \%$ in the 1970 s (Section 5).

The data used are from Nicole Ball (1983) of the National Defense Research Institute of Stockholm and contain observations from 48 LDCs for various years over the period $1950-80 .^{1}$ The regressions reported here are simply time trends, with the dependent variables being relative deviations from overall own-country means, to allow for country-specific factors. It cannot be emphasized too strongly that the results tell us nothing about determinants, only about trends. ${ }^{2}$ They are subject to all the questions always raised by the use of such cross-country, crosstime data. Nevertheless, the trends are sufficiently manifest to suggest the above four stylized facts. These are derived and discussed, in turn, in Sections $2-5$, and the relationship between the four is examined in Section 6.

\section{TOTAL SECURITY EXPENDITURES}

The total national defense expenditures of LDCs are not easy to estimate and, once

\footnotetext{
*I am grateful to Lisa M. Grobar for her assistance; to the Ford Foundation for financial support of a research program on economic issues of national defense in the Institute of Public Policy Studies of the University of Michigan; and to the referees for comments on an earlier version.
} 
estimated, are not of much interest by themselves. To be compared with those of other years, they must be deflated for price changes, and the usually available consumer, wholesale, and national product price indices may provide poor substitutes for the usually unavailable deflator for the military bundle of goods and services. To be compared with those of other countries, they must be converted into a common currency (usually US dollars). The problems of using official exchange rates or purchasing-powerparity estimates are legion, well known, and especially serious for LDCs.

A sensible, if partial, way out of these difficulties is to calculate total security expenditures as a fraction of GDP (hereafter called TSE/ GDP). This is only a partial escape from difficulties for two reasons. One, interpretation of the ratio as a relative real resource flow is implicitly equivalent to using the same price deflator in both numerator and denominator. Two, comparison of the ratio across countries or across time implicitly assumes an income elasticity of demand for national security of unity as the basis for such comparisons.

The ratio, TSE/GDP, ranges in Ball's sample from barely above zero up to one-fourth (for Jordan in the 1970s). It exceeds $10 \%$ persistently for only two countries, Jordan in the 1970s and
Saudi Arabia from the mid-1960s to the mid1970s. For the entire sample of 787 observations, the mean value of the ratio, TSE/GDP, is $3.0 \%$.

In an effort to look for trends among countries that vary so greatly in their average propensity to spend on national security, the percentage deviation of TSE/GDP from its own-country mean is calculated for each country in each year for which Ball provides data. These deviations are then regressed on time and time squared, for the entire sample, and for each of the three regions separately. ${ }^{3}$ The regression statistics are shown in Table 1; the regression curves are graphed in Figure $1 .^{4}$

For the entire sample of countries, and for countries in the Asian and Latin American subsamples, the ratio, TSE/GDP, was stable through the $1950 \mathrm{~s}$ and $1960 \mathrm{~s}$, falling slightly in the $1950 \mathrm{~s}$ and rising slightly in the $1960 \mathrm{~s}$. But it rose rapidly in the $1970 \mathrm{~s}$, with the trend value of TSE/GDP reaching 30-35\% above country means by $1980 .^{5}$ For a typical LDC, for which TSE averaged less than 3\% of GDP in the 1950 s and 1960 s, TSE had risen to 4\% of GDP by 1980 .

In Africa, on the other hand, the rapid rise in TSE/GDP occurred in the 1960s, and the ratio stabilized in the 1970 s. Cross-country regressions like these are not the place to locate motivations and income elasticities, but one might want to

Table 1. Regression trends of TSE/GDP

\begin{tabular}{lcccc}
\hline & Entire & \multicolumn{3}{c}{ Regional samples } \\
Regression ${ }^{*}+$ & sample & Africa & Asia & Latin \\
America
\end{tabular}

*The dependent variable is the percentage deviation of TSE/GDP from its sample own-country mean.

†"Year" is calendar year minus 1980; "year squared" is the square of calendar year minus 1980 . Standard errors are in parentheses.

$\ddagger$ Significant at $99 \%$.

\$Significant at $\mathbf{9 5 \%}$. 


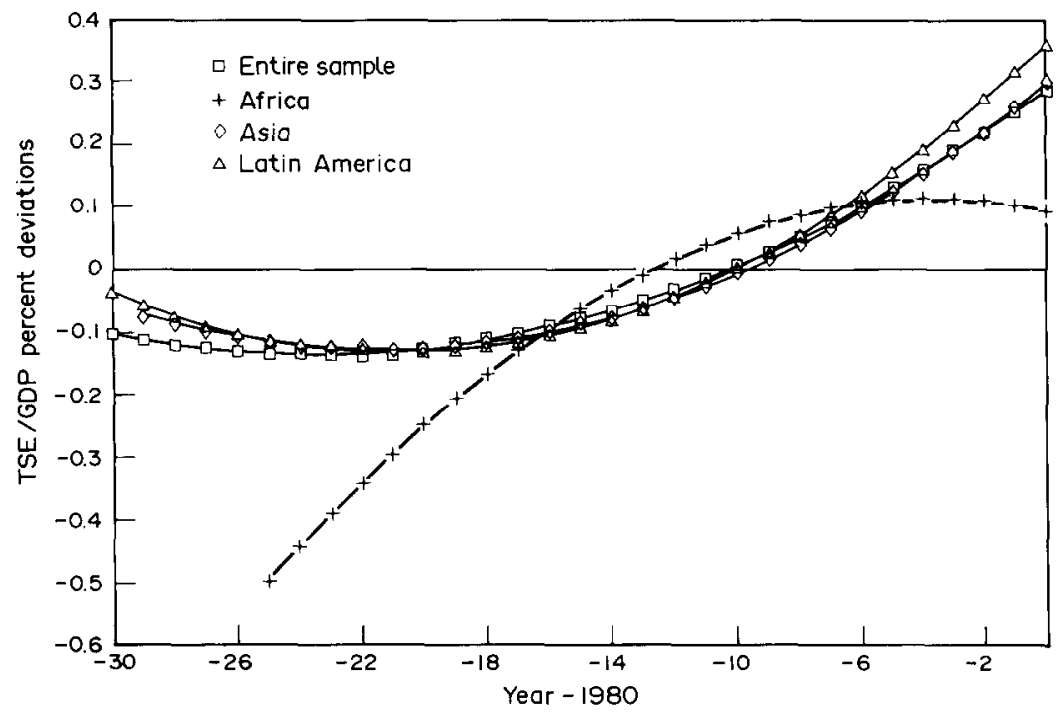

Figure 1. Regressions of TSE/GDP.

note that sub-Saharan Africa experienced not only low growth rates in the 1970 s, but also lower growth rates than those of the $1960 \mathrm{~s} .^{6}$

\section{MILITARY CAPITAL COSTS}

The disaggregation of military expenditure into its current and capital components is not always feasible, and the Ball sample falls from nearly 800 to 700 observations on this account. Not only is the breakdown, in Ball's words, "perhaps not entirely accurate" (Ball, 1983, p. 37), but the totals of the two categories do not always add to the figure for total security expenditure (TSE). The reasons are two: (1) some military expenditures are classified by Ball as "research and development" ( $R$ \& $D)$, an infrequent and always small category in LDCs; and (2) expenditures that "could not be disaggregated" (p. 37) are included in the totals but not in the components. This latter problem is neither infrequent nor small, but its effect on the regressions turns out to be slight.

Data problems notwithstanding, Ball's work in dividing military expenditures into "operating costs" $(O)$ and "capital costs" $(C)$ is especially suggestive for the analysis of LDC security costs. Much of the Benoit controversy over the impact of military expenditure on growth rates hinged on the question whether military expenditure deflected resources from investment or enhanced private capital formation by productively utilizing relatively low-cost resources. While hardly a perfect measure of this, the Ball division of expenditures gets at this distinction. Military capital costs are likely to require scarce foreign exchange or skilled labor, while operating costs are more likely to reflect the direct use of unskilled labor or the acquisition of domestic goods produced with relatively less-skilled labor.

The trends examined here are those in the ratio of capital costs to the total of operating and capital costs $(C /(O+C))$. The importance of country-specific factors in this ratio is great - the overall sample average of $C /(O+C)$ is $12 \%$, but for Iran in the mid-1970s it rose above $70 \%$, and for many other countries it was consistently close to zero. ${ }^{7}$ Because such country-specific factors are important, the percentage deviation of this ratio from the country's own mean ratio is calculated for each country and for each year for which data are available. This percentage deviation is regressed on time and time squared.

The trend regressions are shown in Table 2, and the regression curves pictured in Figure 2.8 While the coefficients are significant, the $R^{2} \mathrm{~s}$ are particularly low. Moreover, for these regressions (and for none of the others), the estimates change dramatically as one removes outlying observations. ${ }^{9}$ In short, the statements of the next few paragraphs are tenuous.

For the entire sample and for each of the regions, a U-shaped curve appears. $C /(O+C)$ is above the country average in the 1950 s, below it in the 1960s, and again above it in the 1970s. LDC militaries were becoming much more capital intensive in the 1970s. The typical LDC, 
Table 2. Regression trends of $C /(O+C)$

\begin{tabular}{lcccc}
\hline & Entire & & \multicolumn{2}{c}{ Regional samples } \\
Regression ${ }^{*} \dagger$ & sample & Africa & Asia & $\begin{array}{c}\text { Latin } \\
\text { America }\end{array}$ \\
\hline Constant & 0.475 & 0.220 & 0.354 & 0.574 \\
& $(0.723)$ & $(0.664)$ & $(0.648)$ & $(0.817)$ \\
Year & $\begin{array}{c}0.0839 \ddagger \\
(0.0134)\end{array}$ & $\begin{array}{c}0.0201 \ddagger \\
(0.00746)\end{array}$ & $\begin{array}{c}0.0736 \ddagger \\
(0.0223)\end{array}$ & $\begin{array}{c}0.0963 \ddagger \\
(0.0242)\end{array}$ \\
Year squared & $\begin{array}{c}0.00271 \ddagger \\
(0.000468)\end{array}$ & $-\$$ & $\begin{array}{c}0.00256 \ddagger \\
(0.000746)\end{array}$ & $\begin{array}{c}0.00298 \ddagger \\
(0.000818)\end{array}$ \\
$\begin{array}{l}\text { Number of } \\
\text { observations }\end{array}$ & 700 & 227 & 200 & 263 \\
$\begin{array}{l}\text { Number of } \\
\text { countries }\end{array}$ & 46 & 17 & 13 & 15 \\
$R^{2}$ & 0.05 & 0.03 & 0.06 & 0.06 \\
\hline
\end{tabular}

*The dependent variable is the percentage deviation of $C /(O+C)$ from its sample own-country mean.

†"Year" is calendar year minus 1980; "year squared" is the square of calendar year minus 1980. Standard errors are in parentheses.

$\ddagger$ Significant at $99 \%$.

\$Omitted (-) if not significant at $95 \%$ when included.

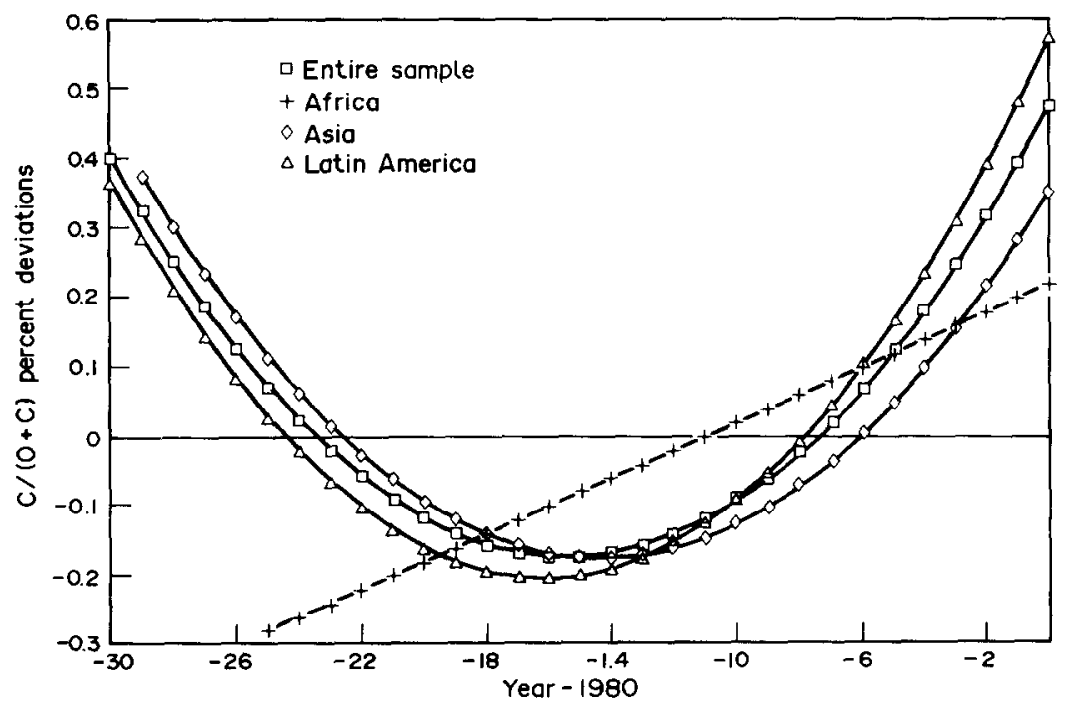

Figure 2. Regressions of $\mathrm{C} /(O+C)$.

which averaged spending barely $12 \%$ of its military budget on equipment over the 1950 s and 1960 s, was spending nearly $20 \%$ by 1980 .

The purpose here is to cxpose stylized facts, not to explain them, but two observations are irresistible.

First, the upturn in the ratio, $C /(O+C)$, occurred at about the samc time that the arms transfer procedures of advanced countries changed. Grants for equipment purchase, which do not show up in the LDC capital-cost figures, gave way to sales. ${ }^{10}$ Moreover, the transfer of old, used, or obsolete equipment gave way to the sale of more expensive equipment embodying 
new technology. Both of these changes may well have contributed to the rise of $C /(O+C)$ in LDCs in the $1970 \mathrm{~s}$, quite independently of any shift in LDC preferences toward a more capitalintensive military establishment. ${ }^{11}$

Second, much of the history of the Benoitinspired controversy about the relation of military expenditures and growth rates in LDCs may be capable of interpretation through this Ushaped trend of $C /(O+C)$ (Benoit, 1973 and 1978). Benoit's data were largely drawn from the mid-1950s to the mid-1960s, a period when LDCs were increasingly incurring operating costs rather than capital costs in their military spending. If such expenditure did not augment growth, it may at least have minimized the adverse effects of such spending on growth by drawing on low opportunity-cost resources. By the $1980 \mathrm{~s}$, when the challenges to Benoit's hypothesis were springing up widely, the data were coming from the 1970 s - when LDC military expenditures were increasingly capital intensive. ${ }^{12}$

\section{MILITARY PERSONNEL}

The importance of national security in a country's labor force allocation is most easily measured by the ratio of armed forces personnel to total population. Even in this straightforward measure, however, there are difficulties. Neither the very young nor the very old are eligible for military duty - nor, in many countries, are women - so total population is not the proper denominator for such a ratio. This we ignore for simplicity. The other difficulty is that the armed forces are only part of the total labor allocated to national security. Unfortunately, it will have to do since estimates, comparable across countries and across time, are not yet collected for the numbers of police and other paramilitary personnel.

The ratio of armed forces personnel to population, Pers/Pop, is again calculated as a percentage deviation of each available observation from its own-country mean. The regressions on time and time squared are shown in Table 3, and the regression curves are pictured in Figure 3. For all, the trend is significantly upward. For Asia, there is little change in the ratio for the $1960 \mathrm{~s}$, but there is an accelerated upward movement in the 1970 s.

The average ratio of armed forces personnel to population for the entire sample is less than $0.40 \%$ (the ratio reaches as high as $3 \%$, for Jordan in the early 1970s). Thus, for a typical country, the regression for the entire sample suggests that the ratio has risen from $0.30 \%$ in

Table 3. Regression trends of Pers/Pop

\begin{tabular}{|c|c|c|c|c|}
\hline Regression ${ }^{*} \dagger$ & $\begin{array}{l}\text { Entire } \\
\text { sample }\end{array}$ & Africa & $\begin{array}{c}\text { egional sam } \\
\text { Asia }\end{array}$ & $\begin{array}{c}\text { Latin } \\
\text { America }\end{array}$ \\
\hline Constant & $\begin{array}{c}0.224 \\
(0.385)\end{array}$ & $\begin{array}{c}0.364 \\
(0.484)\end{array}$ & $\begin{array}{c}0.543 \\
(0.369)\end{array}$ & $\begin{array}{r}0.0779 \\
(0.263)\end{array}$ \\
\hline Year & $\begin{array}{c}0.0232 \ddagger \\
(0.00296)\end{array}$ & $\begin{array}{c}0.0367 \ddagger \\
(0.00644)\end{array}$ & $\begin{array}{c}0.108 \ddagger \\
(0.0226)\end{array}$ & $\begin{array}{c}0.00792 \S \\
(0.00326)\end{array}$ \\
\hline Year squaredi| & - & - & $\begin{array}{r}0.00406 \ddagger \\
(0.00114)\end{array}$ & - \\
\hline $\begin{array}{l}\text { Number of } \\
\text { observations }\end{array}$ & 616 & 212 & 158 & 225 \\
\hline $\begin{array}{l}\text { Number of } \\
\text { countries }\end{array}$ & 45 & 16 & 12 & 15 \\
\hline$R^{2}$ & 0.09 & 0.13 & 0.21 & 0.03 \\
\hline
\end{tabular}

*The dependent variable is the percentage deviation of the ratio, (military) Personnel divided by (total) Population, from the sample own-country mean. †"Year" is calendar year minus 1980; "year squared" is the square of calendar year minus 1980 . Standard errors are in parentheses.

$\ddagger$ Significant at $99 \%$.

$\S$ Significant at $95 \%$.

\|Omitted (-) if not significant at $95 \%$ when included. 


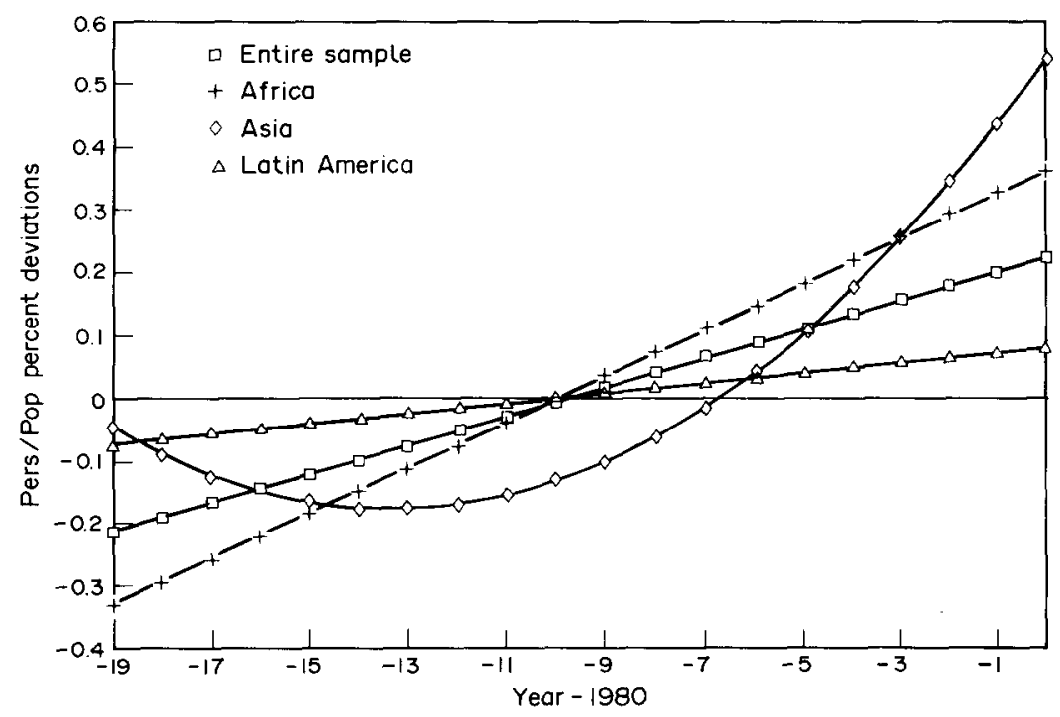

Figure 3. Regressions of Pers/Pop.

1960 to $0.47 \%$ in 1980 - a rise in the ratio of more than one-half over the past two decades.

\section{THE RELATIVE MILITARY "WAGE"}

The military wage rate in $\mathrm{LDCs}$, relative to the average civilian wage rate, is not widely collected information and so to discuss it requires first a search for a reasonable proxy. ${ }^{13}$ The proxy used here, called the relative military "wage" - in quotation marks throughout to remind us of its inadequacies - is the ratio of military operating costs per warrior to the nation's GDP per capita. For (sort of) short, this is written (Op C/Pers)/ (GDP/Pop).

This proxy ratio - technically (Op C/Pers)/ (GDP/Pop) but called the military "wage" will be proportional to the true average military wage rate if three conditions are fulfilled within each of the LDCs considered in the sample: (1) the civilian wage share of total national output is constant over time; (2) the labor force is a constant fraction of the population; and (3) military wage payments are a constant fraction of total military operating costs. ${ }^{14} \mathrm{~A}$ few words on each are appropriate:

(1) Studies of the functional distribution of income indicate that the wage share of national output changes slowly in most countries. For the less than one-third of a century examined here, constancy is not an unreasonable assumption. But the wage share does rise over longer periods of development and may have risen over 1950-80 as the LDCs in this sample have grown. To that extent, movements of the measured military "wage" will provide an upwardly biased estimate of the true average military wage.

(2) The ratio of the labor force to population also moves slowly for most countries. Its movement depends on the labor force participation preferences of working-age persons and on the dependency ratio (i.e., the ratio of the numbers of the very young and the very old to the total population). Examination of these trends indicates that, for most LDCs, the ratio of labor force to population has declined over the past 30 years, largely due to rapid population growth and the resulting growth in the fraction of children in the population. This also will mean that movements of the military "wage" will provide an upwardly biased estimate of the true average military wage.

(3) The "operating cost" data collected by Ball (1983) include not only wage payments but also other noncapital expenditures. To the extent that the latter are nonwage income "perks" - such as food, housing, clothing, and off-duty transport we want them counted into the true military wage. But to the extent that they involve nonconsumption operating costs - such as on-duty transport and ammunition - we should exclude them. If military wage payments, broadly construed, are a rising fraction of total operating costs, then movements of the measured military "wage" will provide a downwardly biased estimate of the true military wage; if military wages are a falling fraction of total operating costs, the 
"wage" will provide an upwardly biased estimate. I suspect the latter tendency but on the basis of little real evidence.

Movements in the relative military "wage" i.e., (Op C/Pers)/(GDP/Pop) - probably overstate the true movements of average military wage rates relative to civilian wage rates. But we will proceed on the assumption that the bias is small enough to be ignored. Only the quotation marks around the word will remain to remind us.

The trends of the military "wage" are reported in Table 4 and displayed in Figure 4, for the entire sample and for each of the regions. The shapes of these trends across the different regions are quite different - for the first time in these pages. The relative "wage" has fallen steadily in Africa, risen steadily in Latin America, and exhibited a steep U-shape in Asia. The entire sample shows a milder U-shape. The trends in each of the regions are consistent with the conjecture that, for the first 20 years or so after independence, $\mathrm{LDCs}$ reduce the military wage to move it from the previous colonial structure toward greater consistency with their own postindependence wage structures. Then the relative military wage begins once again to rise.

Such a rise in the relative military wage may simply reflect increased risk or increased need for loyalty. But it does not necessarily mean that the same structure of warriors is increasingly well paid relative to civilians. At least two other explanations leap forth as possibilities. One, the LDC militaries are becoming increasingly hierarchical. An ever higher ratio of chiefs to braves will raise the average wage with no change in any of the wage rates. Two, the increased capital intensity of the LDC militaries has demanded more highly-skilled personnel to operate and maintain it. The higher average military wage may simply reflect the replacement of lowwage unskilled workers with high-wage skilled workers.

\section{INTER RELATIONS OF THE TRENDS}

In each of the previous four sections, some way of looking at military expenditure in LDCs has been examined for trends. In each, evidence of a disturbing trend has been uncovered. The exposure of these possible stylized facts has been the main purpose of this paper.

Here, we will go a bit further, comparing the trend regressions of the different sections to assess the relative quantitative importance of these different aspects of the growing militaries of LDCs. To do this, compare the percentage growth rate in 1980 implied by each of the regressions of each of the previous four sections. To calculate the 1980 percentage growth rate of

Table 4. Regression trends of military "wage"

\begin{tabular}{lcccc}
\hline & Entire & & \multicolumn{2}{c}{ Regional samples } \\
Regression ${ }^{*} \dagger$ & sample & Africa & Asia & $\begin{array}{c}\text { Latin } \\
\text { America }\end{array}$ \\
\hline Constant & $\begin{array}{c}0.141 \\
(0.401)\end{array}$ & $\begin{array}{c}-0.169 \\
(0.342)\end{array}$ & $\begin{array}{c}0.158 \\
(0.525)\end{array}$ & $\begin{array}{c}0.216 \\
(0.319)\end{array}$ \\
Year & $\begin{array}{c}0.0465 \ddagger \\
(0.0135)\end{array}$ & $\begin{array}{c}-0.0168 \ddagger \\
(0.00495)\end{array}$ & $\begin{array}{c}0.0942 \ddagger \\
(0.0345)\end{array}$ & $\begin{array}{c}0.0217 \ddagger \\
(0.00420)\end{array}$ \\
Year squared 8 & $0.00255 \ddagger$ & - & $0.00625 \ddagger$ & - \\
& $(0.000668)$ & & $(0.00173)$ & \\
$\begin{array}{l}\text { Number of } \\
\text { observations }\end{array}$ & 532 & 185 & 129 & 208 \\
$\begin{array}{l}\text { Number of } \\
\text { countries }\end{array}$ & 44 & 16 & 12 & 15 \\
$R^{2}$ & 0.03 & 0.06 & 0.15 & 0.11 \\
\hline
\end{tabular}

*The dependent variable is the percentage deviation from its own-country mean of (Op C/Pers)/(GDP/Pop).

†"Year" is calendar year minus 1980; "year squared" is the square of calendar year minus 1980. Standard errors are in parentheses.

¥Significant at $99 \%$.

\$Omitted (-) if not significant at $95 \%$ when included. 


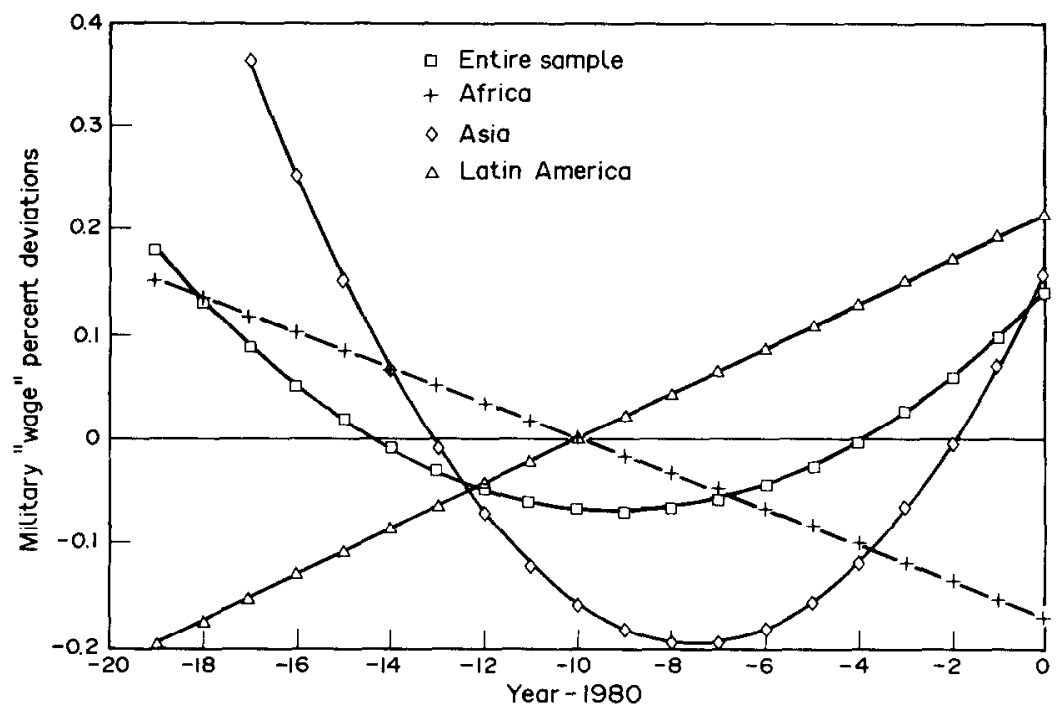

Figure 4. Regressions of military "wage".

any variable $(X)$, consider the basic trend regression (without error term):

$\frac{X_{i t}-\bar{X}_{i}}{\bar{X}_{i}}=\hat{a}_{0}+\hat{a}_{1}(t-1980)+\hat{a}_{2}(t-1980)^{2}$,

where $i$ represents country and $t$ time. (For some regressions, $\hat{a}_{2}$ is insignificant and omitted.) Then,

$\frac{\mathrm{d} X_{i t}}{\mathrm{~d} t}($ for $t=1980)=\hat{a}_{1} \bar{X}_{i}$

and

$X_{i t}($ for $t=1980)=\left(1+\hat{a}_{0}\right) \bar{X}_{i}$ and hence the estimated 1980 growth rate of $X_{i}$ is $\hat{a}_{1} /\left(1+\hat{a}_{0}\right)$.

These growth rates are shown in Table 5 .

For the entire sample, and for the two regions except Africa, the ratio of capital to total military expenditures was rising at a rate above $5 \%$ per annum in 1980. In Asia, the ratio of military personnel to population and the ratio of the average military "wage" to the overall average wage were both rising at rates of $7-8 \%$ in 1980 . Only in Africa was the ratio of total security expenditures to GDP falling; elsewhere, this ratio was rising at a rate above $3 \%$ in 1980 .

Table 5. 1980 Growth rates of military ratios implied by the regressions

\begin{tabular}{|c|c|c|c|c|c|}
\hline \multirow[b]{2}{*}{$\begin{array}{l}\text { Ratio } \\
\text { variable* }\end{array}$} & \multirow[b]{2}{*}{$\begin{array}{l}\text { Section } \\
\text { discussed }\end{array}$} & \multirow[b]{2}{*}{$\begin{array}{l}\text { Entire } \\
\text { sample }\end{array}$} & \multicolumn{3}{|c|}{ Regional samples } \\
\hline & & & Africa & Asia & $\begin{array}{c}\text { Latin } \\
\text { America }\end{array}$ \\
\hline $\begin{array}{l}\text { Total security } \\
\text { expenditure }\end{array}$ & 2 & $2.78 \%$ & $-0.89 \%$ & $3.03 \%$ & $3.45 \%$ \\
\hline Military capital & & & & & \\
\hline costs & 3 & $5.69 \%$ & $1.65 \%$ & $5.44 \%$ & $6.12 \%$ \\
\hline Military personnel & 4 & $1.90 \%$ & $2.69 \%$ & $7.00 \%$ & $0.73 \%$ \\
\hline Military "wage" & 5 & $4.08 \%$ & $-2.02 \%$ & $8.13 \%$ & $1.78 \%$ \\
\hline
\end{tabular}

*The definitions of the ratios (by section discussed):

2. TSE/GDP; 3. $\mathrm{C} /(O+C)$; 4. Pers/Pop; and 5. (Op C/Pers)/(GDP/Pop).

Source: Regressions of Tables 1-4. 
Almost throughout the less developed world, these indicators of relative allocations to defense were rising at rates of $2 \%$ to $8 \%$ per annum by 1980.

The numbers are high, and alarming, but they are only estimates; and the magnitudes of the standard errors of the constant terms in the regressions mean that they are only very rough estimates. One consistency check can be utilized to make this warning clear. The four ratios examined separately in Sections $2-5$ are - as alert readers may have noticed - not independent of each other. Algebraic manipulation shows that

$\frac{\mathrm{TSE}}{\mathrm{GDP}}=\frac{\left[\frac{\text { Op } C / \text { Pers }}{\mathrm{GDP} / \text { Pop }}\right] \cdot\left[\frac{\text { Pers }}{\text { Pop }}\right]}{(1-[C /(O+C)])}$,

provided that $(O+C)=\mathrm{TSE}$, as in principle it should. ${ }^{15}$ In fact, $(O+C)$ is often smaller than TSE because expenditures that Ball was unable to allocate were included in TSE but neither in $O$ nor in $C$. Ignoring this, taking logarithms of equation (4) and differentiating, one reaches a growth rate identity:

$G\left(\frac{\text { TSE }}{\text { GDP }}\right)=G\left(\frac{\text { Pers }}{\text { Pop }}\right)+G\left(\frac{\text { Op } C / \text { Pers }}{\text { GDP/Pop }}\right)+$

$$
\frac{C /(O+C)}{[1-C /(O+C)]} G(C /(O+C))
$$

where $G($.$) means estimated percentage growth$ rate of the parenthetical ratio. The averages over $1960-80$ of the two sides of equation (5) are shown in Table 6. The right-hand side is higher in every sample except that for Asia. ${ }^{16}$ This second (i.e., right-hand) estimate in Table 6 of the same variable - the average growth rate over 1960-80 of TSE/GDP - reemphasizes the roughness of these trend calculations, but offers no suggestion that the earlier estimates were too high.

Table 6. Consistency checks on regression trends

\begin{tabular}{|c|c|c|}
\hline \multirow[b]{2}{*}{ Sample } & \multicolumn{2}{|c|}{ Side of equation $(5)^{*}$} \\
\hline & Left hand & Right hand \\
\hline Entire & $1.91 \%$ & $2.36 \%$ \\
\hline Africa & $1.88 \%$ & $2.46 \%$ \\
\hline Asia & $1.93 \%$ & $0.29 \%$ \\
\hline Latin America & $2.22 \%$ & $3.42 \%$ \\
\hline
\end{tabular}

* The weight on the final term of equation (5) is 0.1364 , the overall sample average of the value, for each of the four samples.

Source: Tables 1-4.

\section{NOTES}

1. In certain of the regressions below, these data are supplemented with information from the World Bank (IBRD, 1983), the International Monetary Fund (IMF, 1981), and the ISS Arms Control and Disarmament Agency (ACDA, various years). See Appendix A for fuller discussion of the data.

2. Moreover, one cannot naively extrapolate these trends. Although the data for the $1980 \mathrm{~s}$ are just appearing, there are already hints that the trends reported here are not abating - Deger (1986), for example reports that real military expenditure in LDCs rose $20 \%$ between 1980 and 1983 .

3. The regional groupings are those selected by Ball. She counts also the region "Middle East," but it includes only two countries and is hence not used here. The data for these two countries are in the "entire sample."

4. The horizontal axis of all of the graphs shown here is Year-1980, the same time variable that appears in the regressions. The graphs are only shown for the years in which there is at least one observation in the relevant sample. Notice that the low $R^{2}$ values in this and subsequent tables occur because the dependent variable is the percentage deviation from the owncountry mean. If the actual dependent variable were used and country dummies incorporated, the $R^{2}$ values would run between 0.65 and 0.95 throughout. This format focuses narrowly on the time effects.

5. The definition of the independent variables makes the constant term of each regression the estimated 1980 value of the dependent variable.

6. Maizels and Nissanke (1986) speculate on interregional differences in the determinants of this military expenditure as a percentage of GDP.

7. For nearly one-fifth of the observations, the ratio was less than $2 \%$.

8. Notice that the number of observations usable in these regressions is fewer than in Table 1 . While I think we should use all the data available, Appendix B reworks all the text regressions using only the observations common to all.

9. When residuals (for the entire sample) as large in absolute value as $100 \%$ are removed, the regression becomes:

$$
C /(O+C)=\underset{(0.446)}{-0.195}-\underset{(0.00909)}{0.0121}(t-1980)-
$$


$0.000420(t-1980)^{2}$

$(0.000316)$

with standard errors in parenthesis. $R^{2}=0.00$.

10. Often on soft-interest and deferred-payment bases, which also reduce the LDC figures but not by so much.

11. For history and discussion of the move from grants to sales and from old to new, see Mosley (1985) pp. 140 ff., Nincic (1982) pp. 144 ff., Graves and Hildreth (1985) Chapter 1, Labrie et al. (1982), and Klare (1984) pp. $40 \mathrm{ff}$.

12. For a review of the testing of Benoit's hypothesis, see Grobar and Porter (1989).

13. This entire section refers to the average military wage rate. A change in the hierarchical structure of the military will change this even with no change in any military pay rates.

14. The first and sccond of these threc conditions could be avoided by using some average (say, industrial) wage rate as the denominator (in place of GDP/Pop). While it is easy to find such series for most LDCs, it is not easy to be sure that they are comparably calculated across countries.

15. Almost - remember, $\mathrm{R} \& \mathrm{D}$ expenditures are excluded from $(O+C)$ but not from TSE; but such $R$ \& $D$ is small in LDCs. See Ball (1983) passim.

16. A part of the difference can be attributed to the failure of $(O+C)$ to equal TSE. (Ironically, despite ever improving LDC data services, Ball experienced increasing rather than decreasing difficulty over 195080 allocating TSE between $O$ and $C$.) The weak fit of the $C /(O+C)$ regressions accounts for much of the difference.

\section{REFERENCES}

Arms Control and Disarmament Agency (ACDA), World Military Expenditures (Washington, DC: ACDA, various years).

Ball, N., Third-World Security Expenditure: A Statistical Compendium (Stockholm: Swedish National Defense Research Institute, July 20, 1983).

Benoit, E., "Growth and defense in developing countries," Economic Development and Cultural Change, Vol. 26, No. 2 (January 1978).

Benoit, E., Defense and Economic Growth in Developing Countries (Lexington, MA: Lexington Books, 1973).

Deger, S., Military Expenditures in Third World Countries: The Economic Effects (London: Routledge and Kegan Paul, 1986).

Graves, E., and S. A. Hildreth (Eds.), U.S. Security Assistance: The Political Process (Cambridge, MA: Lexington Books, 1985).

Grobar, L. M., and R. C. Porter, "Benoit revisited: The effect of defense spending on economic growth in LDCs," Journal of Conflict Resolution (June 1989).

International Bank for Reconstruction and Development (IBRD), World Tables, 3rd ed. (Washington, DC: World Bank, 1983).
International Institute of Strategic Studies (IISS), The Military Balance (London: IISS, various years).

International Monetary Fund (IMF), International Financial Statistic Yearbook, 1981 (Washington, DC: IMF, 1981).

Klare, M. T., American Arms Supermarket (Austin, TX: University of Texas Press, 1984).

Labrie, R. P. et al., U.S. Arms Sales Policy: Background and issues (Washington, DC: American Enterprise Institute, 1982).

Maizels, A., and M. K. Nissanke, "The determinants of military expenditures in developing countries," World Development, Vol. 14, No. 9 (1986), pp. 1125-1140.

Mosley, H. G., The Arms Race: Economic and Social Consequences (Cambridge, MA: Lexington Books, 1985).

Nincic, M., The Arms Race: The Political Economy of Military Growth (New York: Praeger, 1982).

Stockholm International Peace Research Institute (SIPRI), World Armaments and Disarmament: SIPRI Yearbook (Stockholm: SIPRI, various years).

\section{APPENDIX A: THE DATA}

The principal source of the data is Ball (1983). The data sources and problems are described fully there and hence need only brief discussion here. The data cover 48 less developed countries (LDCs) and various years over the period 1950-80. These were the countries for which "it was possible to obtain data... which covered much of that period" (Ball, 1983, p. 34). In principle, this provides 1,488 observations on national security expenditures; in fact, Ball presents quantita- tive information for total security expenditure in only 804 cases. $^{17}$

There are two advances made by this data effort beyond the sheer number of LDCs and years covered:

(1) Security expenditures are disaggregated. The principal disaggregation is between operating (i.e., current) and capital (i.e., equipment) costs. (This distinction is utilized in Sections 3 and 5.) The exact 
distinction is inevitably fuzzy, especially where rapidly depreciating or obsolescing military equipment is involved.

(2) The security expenditure data are checked against the other usual sources and as a result presumably represent the best, qualitatively as well as quantitatively, that are available to us in the mid-1980s. ${ }^{18}$

No doubt there is bias in this expenditure data. First, since many LDCs are reluctant to broadcast the structure and extent of their military forces, there is direct under-reporting, with many expenditures being hidden, reported as nonmilitary, or paid for by offbudget agencies. Second, military gifts from abroad and military purchases with payments deferred are rarely included in LDC budget statements. ${ }^{19}$ Thus, the Ball figures for security expenditures must be recognized as lower-bound, at best.

Whether the downward bias has increased or decreased over time is unclear. Military gifts have become less common over the period $1950-80$, but low-interest deferred payments more common. The trends of "hidden expenditures" are quite unknown. The text implicitly assumes that the extent of the bias has not changed (or has increased, in which case the trends uncovered in the text are even more alarming).

Ball collected the data for each LDC from the country's own sources. Thus, neither the concepts nor the practices of data collection are comparable across countries. There is also incomparability across years within countries, but to a much smaller degree. Thus, all the calculations of the text deal with each variable's percentage deviation from its own-country mean (across all the years available for that country for that variable). This all but eliminates the risk that the estimated trends arise through coincidental appearance and disappearance of particular countries in the sample.

The regressions of the text utilize three data series from sources other than Ball:

(1) $G D P$, from IMF (1981)..$^{20}$

(2) Military personnel, from ACDA (various years). These data are for armed forces personnel only and do not include police or other paramilitary personnel. The data are not available before the $1960 \mathrm{~s}$.

(3) Population, from IBRD (1983). ${ }^{21}$

In each section of the text, all observations are utilized for which all the needed data are available in these sources. Data absences account for the different number of observations in the regressions of the different sections.

\section{NOTES TO APPENDIX A}

17. "The only criterion used in choosing the data presented ... [was] availability" (Ball, 1983, p. 35).

18. The usual sources are three: (i) the US Arms Control and Disarmament Agency (ACDA); (ii) the International Institute of Strategic Studies (IISS); and (iii) the Stockholm International Peace Research Institute (SIPRI). Security expenditure data are available from these three sources for comparison purposes since 1961,1972 , and 1952, respectively.

19. Such gifts and purchases are, in principle, counted as expenditures by the donor (or lending) country. From one viewpoint, this treatment is quite correct - it avoids global double counting. But even gifts impose burdens, and the result here is under-reporting of military resource allocation.

20. Some of the GDP data are taken from other sources. Exact source for each country and year is reported in Ball (1983).

21. Data for Guyana from IMF (1981). Intraquinquennial figures are interpolated log-linearly.

\section{APPENDIX B: REGRESSIONS USING ONLY COMPLETE OBSERVATIONS}

There are 804 observations of total security expenditures (TSE) in Ball's data set. But in each of the regressions performed in the text, some additional information on the observations is needed, and gaps in the availability of this additional information means that the usable number of observations varies from section to section. At the extreme, there are only 532 observations in the regressions of Table 4 .

One feels uncomfortable using different observations in the different regressions, even though a lot of information is discarded if only those observations are used which can be used for all the regressions - barely 400 of them - half the original sample of TSE information. But one would feel even more uncomfortable if the results were highly dependent on the vagaries of the sample size. So the regressions for the entire sample (of complete observations) were repeated for each of the four ratio variables discussed in Sections 2-5. These regressions are given in Table B-1, and the regression lines are pictured in Figure B-1.

Most noticeable is that the regressions never involve a significant quadratic time-trend term. But recall that all of the data from the $1950 \mathrm{~s}$ are discarded in this reduced sample since no military personnel data are available before 1961. Two decades are just not long enough to produce significant curvature in the trends. But the general slopes are very similar for the 1960 s and 1970 s in Figure B-1 and in the previous four figures (for the "entire sample" regressions). The only exception is the military "wage" regression, which here has a slight and insignificant negative slope. 
Table B-1. Regression trends on entire sample of complete observations

\begin{tabular}{lcccc}
\hline Regression ${ }^{*} \dagger$ & TSE/GDP & $\mathrm{C} /(O+C)$ & Pers/Pop & $\begin{array}{c}\text { Military } \\
\text { "wage" }\end{array}$ \\
\hline Constant & 0.159 & 0.311 & 0.138 & -0.0304 \\
& $(0.264)$ & $(0.720)$ & $(0.257)$ & $(0.277)$ \\
Year & $0.0161 \ddagger$ & $0.0316 \ddagger$ & $0.0140 \ddagger$ & -0.00308 \\
& $(0.00254)$ & $(0.00692)$ & $(0.00247)$ & $(0.00266)$ \\
$\begin{array}{l}\text { Number of } \\
\text { observations }\end{array}$ & 398 & 398 & 398 & 398 \\
$\begin{array}{l}\text { Number of } \\
\text { countries }\end{array}$ & 37 & 37 & 37 & 37 \\
$\hat{a}_{1} /\left(1+\hat{a}_{0}\right)$ & $1.39 \%$ & $2.41 \%$ & $1.23 \%$ & $-0.32 \%$ \\
$R^{2}$ & 0.09 & 0.05 & 0.08 & 0.00 \\
\hline
\end{tabular}

*The dependent variable is in each case the percentage deviation from its owncountry mean.

†See Table 1 , note $\uparrow$.

$\ddagger$ Significant at $99 \%$.

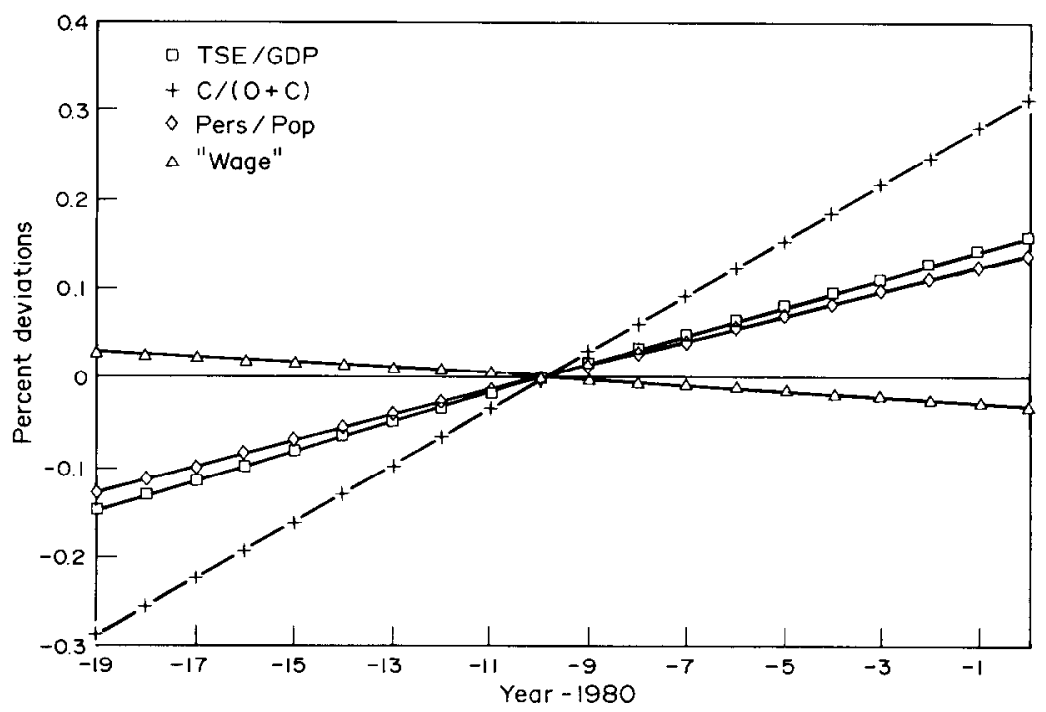

Figure B-1. Regressions on sample of complete observations. 